\title{
Research on the Development Strategy Planning of Wuhan's Incubators
}

\author{
Juan Li \\ School of Management, Wuhan University of Technology, Wuhan, China \\ (1905239854@qq.com)
}

Keywords: Incubator; Development strategy; PEST analysis; SWOT analysis

\begin{abstract}
After reviewing macro-environment, this paper analyzed its development opportunities and threats, then using the SWOT analysis model to get the incubators' strengths, weaknesses, opportunities and challenges, and then, from ST, SO, WO, WR four aspects to make strategic combination, and put forward four kinds of alternative strategy, for further to realize the overall goal for "13th five years" strategy. Finally this paper raised the detail measures for strategy implementation and related guarantee measures.
\end{abstract}

\section{Introduction}

During the period of "13th five years", the technical innovation drives China's economic and social development. In the past few years, Wuhan incubator has gained great development, also facing upcoming future opportunities and challenges, development strategy research incubator industry in Wuhan is also very important.

\section{Macro Environment Analysis (PEST Analysis)}

General environmental factors, also known as the macro environment, refer to the social environment factors which can affect an industry [1].

Political environment. Recently, Wuhan governors have attached much importance to the construction and development of business incubators, issuing several incubator policies. In 2014, to stimulate college students' entrepreneurship, Wuhan government decided on a plan of implementing college students' entrepreneurship "Qing Tong", and put forward a series of ideas to support students' entrepreneurship, greatly promoting the college students' entrepreneurial passion.

Economical environment. In 2015, the GDP of Wuhan totaled 4,479.237 billion, of which three industries grew by $4.6 \%, 11.6 \%$ and $9.8 \%$ respectively over the previous year. The three industrial structures were adjusted from 3.5: 47.5: 49.0 in the previous year to 3.3: 45.7: 51.0. In the "12th Five-Year Plan" period, the general public budget revenue of the city increased by an average of $17.6 \%$ annually, of which the average local public budget revenue increased by $21 \%$ on average. Overall, Wuhan has developed rapidly, the economic structure has become more rational, the proportion of the tertiary industry has increased, the level of economic development has become more stable, the resources have become more diversified, the policies have become more perfect and the development trend has been good in the future.

Social cultural environment. In terms of educational level, Wuhan is the "city of universities," with 80 colleges and universities and more than 300,000 university graduates each year. A large number of high-quality talent for start-ups provided a rich talent pool. To promote innovation and entrepreneurship, talent is the key, culture is the support. The spirit of Wuhan, "dare to be the first, the pursuit of excellence", inspired everyone, under the leadership of the spirit, Wuhan has held a series 
of activities to create a social entrepreneurial atmosphere such as "Qing Tong" and "Pioneer of college students" selection.

Technological environment. The era of globalization drives not only innovation and development of science and technology, but also more enterprise's core competitiveness [2]. In general, the overall strength of Wuhan's science and education goes after Beijing and Shanghai. Wuhan awarded 404 items of scientific and technological achievements, of which 26 national awards, 2182 implementation of the municipal science and technology plan projects, the municipal register 304 items of scientific and technological achievements. The whole year of high-tech industry output value in Wuhan reached 770.141 billion, $14.1 \%$ over the previous year.

\section{Internal Factors Analysis}

The development of an enterprise is restricted not only by the external environment factors, also by internal ability. From Wuhan incubator under the operating mechanism, the innovation performance, the three aspects such as the incubation performance to specific internal environment analysis. Due to the limited data collection, this article only choose some data for analysis.

Operation and service. Taking Wuhan university of science and technology incubator, for example, Wuhan university of science and technology incubator provides not only hatching area and property management, web services, project services, consulting services, intermediary services, investment and financing services, training services and other basic services, also provides the information service and technical service, with Wuhan university of science and technology and VIP data, the data of ten thousand and the library of Wuhan university of science and technology resources such as entrepreneurs to provide convenience to the park, greatly promote the Wuhan institute of technology incubator hatching efficiency.

Innovation performance. According to the torch center related data compiled in this paper, including Beijing, Shanghai, Tianjin, Chongqing, 18 first-tier and second-tier cities on an application for a patent for invention, the invention patent authorization and effective number of invention patents, and sorting, number of an application for a patent for invention for the 14th in Wuhan city, the number of invention patents authorization for the 11th, effective number of invention patents for the 10th, in general, the level of invention patent in Wuhan city in the middle and lower levels, and Beijing, Shanghai and other first-tier cities in number still has certain gap.

The incubation performance. This paper has collected 2011 Nanjing, Shanghai, Hefei and Wuhan city of four hatching performance key indicators, through comparative analysis of Wuhan hatchability overall have certain advantages, compared with Nanjing, Hefei, Wuhan national incubator number than both, but has certain gap compared with Shanghai, the hatch venue, incubation fund, the income and incubated enterprises staff, incubator in Wuhan city is more than the other three cities including Shanghai, on a number of intellectual property rights, and there is no advantage in Wuhan city.

\section{Analysis of the Development Strategy}

SWOT analysis. SWOT is a comprehensive evaluation of the S (Strong), W (Weakness), O (Opportunity) and $\mathrm{T}$ (Threat), both considering the external environment and internal conditions, to select the best method of operation strategy [3]. 
Table 1 SWOT analysis diagram

\begin{tabular}{|l|l|}
\hline S:(1) location advantage & W:(1) the management team is not enough \\
(2)the incubator & (2) service system not perfect \\
persistent development & (3) into the hatch companies growth can't keep up with \\
history & hatching area of growth \\
\hline O:(1)industry prospects & $\mathbf{T}:(1)$ the fierce competition in the industry \\
and wide development & (2) the institutional restriction incubator development \\
(2)strengthening & (3) the lack of specialized and socialized service \\
government support & (4) the personnel quality needs to be improved \\
\hline
\end{tabular}

SO strategy. (1)Reasonable institutional innovation. Change the role of the government, who were responsible for the incubator. If the enterprises take the response of incubator with the government departments, they will be more conducive to innovation development of the incubator [4]. (2)Attach great importance to the construction and improvement of incubator network. With the globalization coming, information network has been used more frequently. Several incubators have conducted network data services, although not complete and not playing full role of the network. Overall, the incubator must pay more attention to the construction of information network, including the establishment of internal websites, all kinds of informal organizations and activities, to build a free exchange platform, and give full play to the incubator cluster advantages. (3)Care more about the cultivation of the incubator enterprise culture. Contributing a good corporate culture means respecting knowledge, respecting talent, respecting entrepreneurship and tolerance of failure.

ST strategy. (1)The innovation of service model. Due to its limited resources, the incubators can't provide all the services for its enterprises, which requires the incubator to establish public service platform, using the social resources to service for the incubators, such as conducting a "officer, production, campus, research, mediation, trade" mutual beneficial public service platform, fully implement the government policy, reasonable use of government resources, and maintaining communication with scientific research institutions and universities, and so on.(2) Realize the coordinated development of regions. Because of the differences in regional economic development and the natural environment, the incubator may communicate with other incubators through the incubator platform to make the strategic alliance, eventually realize common development.

WO strategy. Attach much importance to the cultivation of talents, provide various preferential policies of talents cultivation, and the talent market at various levels shall recommend the excellent talents for the incubator and the incubated enterprises, providing services such as recruitment and training, what's mare, the related departments should strengthen organizational training, in order to enhance the management level [5].

WT strategy. Improve the quality of the staff and strengthen the introduction of professionals. The Wuhan, called as "university city", should make full use of its advantages, improving personnel quality of the internal management team, regularly training management personnel, also introducing the domestic and foreign talents, studying the excellent management case abroad actively.

\section{Development Strategy and Implementation}

Strategy determination. During the period of "13th five years", Wuhan, as the center of innovation development, should keep up with the development of the market environment, and positively carry on the innovation and development, in order to promote the comprehensive strength, besides, the incubator must carry on the strategic transformation of incubator, that is the government and the 
market work together, instead of domination by the government, giving full play to the market---the "invisible hand". According to the SWOT comprehensive analysis, we can see that, to successfully achieve strategic transformation, we must take advantage of government support. Thus, this paper proposes the development strategy, based on the angle of the government innovation strategy, to provide a good macro environment for Wuhan incubators' industrialization development.

The implementation. We can conduct innovation strategy from the following several aspects: (1) Strengthen the construction of the institutional environment. Construction of the institutional environment construction is carried out in two aspects: the perfect institutional system and the execution of the system. Although our government has introduced many policies, in terms of risk investment system and the further development of space, it's also necessary to strengthen policy enforcement, ensure each preferential policy [6]. (2) Build a multi-level talent incubator system. Modern society has increasingly needed high-quality comprehensive talents. Thus building a multi-level talent cultivation system and cultivating comprehensive talents fully mobilize enthusiasm and creativity of the entrepreneurs and investors. (3) Establish a strict evaluation system to incubator performance. To ensure both the increasing number of incubators in Wuhan and the quality of the incubators, the government must establish a strict incubator performance evaluation system, rewarding good-performance incubators and appropriating out the poor incubators, to guarantee the comprehensive development of incubators in Wuhan. (4) Explore an industrialized innovation model based on the government. Under the guidance of industrialization form of system government to encourage exploration "incubator", making perfect business service chain and promoting the enterprise incubator cluster form provide powerful service support for entrepreneurial economy [7].

Strategic safeguard measures. To ensure the successful implementation of the strategy, we can take the following measures: (1) Complete hardware facilities. Frist, the regular inspection basic hardware facilities ensures the safety of incubator working environment; Second, establish a strict hatcheries park security system, to ensure the safety of the park; Third, improve the park natural scenery, to make everyone in the best working state and improve the brand image. (2) Guarantee policy support. The incubator strategy implementation can't depart from the support of government departments, as well as the relevant policies [8]. To ensure the effective implementation of incubator development strategy in Wuhan, the government should do some things from the following points: make relevant policy rules, promote the incubator innovation system reform; provide support for the incubators on resources and services; Government actively coordinate regional incubator mutual exchanges and cooperation, common development so on; pay attention to moderate government regulation. (3) Ensure perfect talent incentive mechanism. Establishing a rigorous talent incentive mechanism will be helpful to keep the staff in the incubator, mobilize their enthusiasm, and attract more talents to join the incubator [9]. Perfecting the incentive mechanism can begin from the following aspects: the reasonable design of compensation, improving the appraisal indicators, benign promotion mechanism, not only to increase staffs' identity to enterprise, also to increase employees' satisfaction. (4) Assure enough money. To solve the problem of funds, the incubators in Wuhan need take various measures to establish unblocked financing channels, to get more investment and financing. The most important thing is to integrate various resources, applying the limited resources to places where they are needed most, to achieve maximum benefit. 


\section{Conclusion}

In this paper, through the SWOT analysis, as well as comprehensive analysis of the external environment and internal ability, we found out the opportunities and threats of incubators in Wuhan city, the advantages and disadvantages, the formation of suitable development strategy of incubator [10]. According to the actual situation of incubator in Wuhan city, this paper put forward the most suitable strategy from the four kinds of alternative strategies, including the institutional environment, a multi-level talent incubator system, a strict evaluation system to incubator performance and an industrialized innovation model based on the government. Finally, put forward strategic and strategic implementation safeguard measures, to lay the foundation for Wuhan incubator deeper research.

\section{References}

[1] Jun Li: China's New Technology and New Products, (2007) No.12, p.51 and 55. (In Chinese)

[2] C. Wang: Journal of Business Review, (2014) No.22, p.84-85.

[3] Z.G. Yue and Y.H. Hou: Science and Technology Progress and Countermeasures, Vol. 28 (2011) No.9, p.152-156. (In Chinese)

[4] H.J. Hao and Y. Liu: Science and Technology and Management, Vol. 15 (2013) No.2, p.111-114. (In Chinese)

[5] P. Voisey, P. Jones and T. Brychan: Industry and Higher Education, Vol. 27 (2013) No.5, p.349-363.

[6] Y. Chen: Science and technology and management, Vol. 9 (2007) No.3, p.137-139. (In Chinese)

[7] Y.Q. Zhang, A.J. Liu and L. Xu: Journal of Jiangxi Agricultural, Vol. 21 (2009) No.4, p.159-161. (In Chinese)

[8] W. He: Group Economic Studies, Vol. 35 (2007), p.345-346. (In Chinese)

[9] Z.H. Qian: Journal of Beijing University of Science and Technology (Social Science Edition), Vol. 27 (2011) No.2, p.86-92. (In Chinese)

[10] Y. Liu and H. Fu: Journal of the Chinese market, Vol. 40 (2010), p.49-51. (In Chinese) 